\title{
Emotional Intelligence and Stress: An Analytical Study of Pakistan Banks
}

\author{
Saddam Hussain Rahim
}

\begin{abstract}
The biggest killer is not AIDS or cancer but psychological problems, and we see that very high level of stress found in bank employees. The banking sector is becoming increasingly competitive around the country and the level of product and service quality being offered to customer is almost same. Hence, the bank management adds more responsibilities on the shoulders of employees, resulting into a pressure on them, with increasing psychological problems i.e. stress, strain, anxiety, depression, sleep disorders, etc. This situation, in which the employees have little or no sense of identification with their job, can cause an individual looking for another job or don't perform efficiently their own. Therefore, it is very difficult for management that how maintains bank employees' ability to develop successful performance with their organization under present conditions? Since the 1990s, the subject of Emotional Intelligence (EI) has gradually become the concern of academics and researchers for the impact on stress. This article also demonstrates that EI competencies have the profound impact on stress. It is noted that very little research has examined EI skills in the banking sector while in Pakistan, there is no research that examines the impact of EI competencies to prevent stress among bank employees. This study carries out to assess the relationship of EI competencies and stress among the bank employees who work under stressful conditions.
\end{abstract}

Index Terms-Emotional Intelligence, Stress, Banking Sector of Pakistan

\section{INTRODUCTION}

Stress affects the employees' performance that indirectly affects the organization survival because if employees reduce their work efficiency and can't work best for their organizations, so this situation couldn't be only affected the organizational performance but also lost healthy shares in an increasingly competitive market, and may even jeopardize their survival (Kazmi, 2008). It is therefore, an essentials task for management to deal effectively and prevents this suffering. It is the responsibility of management to fight against the stress at work, to identify the suitable course of action and solve them. Improving stress prevention is a positive action that contributes to a better health of workers and generates great organization efficiency and performance.

It is an empirical study to analyze the relationships between EI competencies and stress in terms of the banking sector of Pakistan. There are almost more than 9,000 branches consist of approximately 130,000 employees throughout the country of different local and international

${ }^{1}$ Economic Survey of Pakistan 2008 - 09, Ministry of Finance, Government of Pakistan. banks. Although there are numerous occupational problems are being faced by employees in banks. However, stress is very common in bank employees due to multiple reasons, which demand the solution on the priority basis. For this, the EI competencies found very effective to prevent stress among employees (Salovey, Stroud, Woolery \& Epel, 2002, Ciarrochi, Deane, \& Anderson, 2002). Therefore, it attempts to establish the linkage between EI competencies and stress, especially in the context of the banking sector of Pakistan.

\section{The BAnking Sector of PAKISTAN}

Pakistan is a very important country of the South Asian region. It has a mixed economy i.e. the textile's sector, the sports goods industry, the agriculture sector, the services sector and other industries. The well-developed banking sector of Pakistan keeps the largest share in the service sector and gradually growing very fast. After the privatizations reforms, the banking sector of Pakistan has been transformed from a lethargic and slowing moving sector to an energetic, competitive and lucrative industry. The recently growth is highly appealing to foreign investors for investment in the banking sector. This sector has been rising at an average rate of $23 \%$ per annum over the last five years. The financial sector assets have been risen up to 1800 million dollar in fiscal year 2007-08. The industry size is reaching to approximately five trillion rupees over the last five years ${ }^{2}$, which shows very impressive and sound growth in the banking sector.

Although the banking sector is growing very fast and providing vast opportunities of employment. However, the psychological problems i.e. stress, strain, anxiety, etc., may break the growth of the banking sector. The empirical observation reveals that there is common the overloading and extreme burden of work, strictly time pressure of completion of tasks, more than 12 hours of work duration, long travel, fear of termination of job contract, etc. As a result, we observe that employees suffer in extremely high level of stress. Despite the researchers have produced numerous programs for prevention of stress in developed countries, which are also being implemented but under-developing countries like Pakistan, we are so far behind. In Pakistan, the numerous reform's programs are just limited to improve the financial performance, innovation of new products, improve the building infrastructure, espouse the modern practices, the different training programs, etc., but they are yet to start any reform program, which is relevant to employees' psychological problems. 
Although the contemporary practices have replaced the traditionally practices of banking but the working nature is still unchanged and problems are still unresolved. It is common to observe too frustrated employees in banks, and they just do the job for their financial problem and to support family. The empirical observation reveals that the stress factor is gradually destroying the employee ability to work, i.e. producing them in a bad mood, fatigue, lack of will to develop the tasks, depression, sleep disorders, etc. This situation, in which the employees have little or no sense of identification with their job, can cause an individual looking for another job or don't perform efficiently their own. However, if we identify the solution, we can provide a helping hand in order to prevent stress. The present circumstances recommend that policy makers must be paid attention in this regard that may significantly curb the productivity of its bank employees and wears them mentally harm.

\section{EMOTIONAL INTELLIGENCE AND STRESS}

Stress is considered to be one of the main themes in the research for last two decades and a significant growth observe in researchers' interest as a concern to both employers and employees (Hochwarter, Perrewe, Meurs \& Kacmar, 2007, Cartwright, 2000). Stress is the destructive physical, mental and emotional reaction that transpires when there is a poor match between job demands and competencies or employees' resources to manage with job pressure. It is a condition ushered by suffering physical, mental, psychological or social problem that comes from individual feeling that doesn't be able to respond due to unexpected situations. The basic root cause of stress in the organization, when employees face difficulties and changes in his daily working routine but always avoid and this condition creates stress, anxiety, fears, worries, tension, etc. (Akinboye, Akinboye \& Adeyemo, 2002).

Recently studies have shown great researchers' interest in the study of the relationship between EI and stress in the light of organizational performance and several studies investigated the impact of EI competencies on stress, which report the existence of positive relationship (Gardner, 2005, Spector and Goh, 2001, Ciarrochi, Chan, \& Bajgar, 2001). The EI competencies play a role to create the abilities in an individual's to better control the stress in the workplace. The previous studies reveal that the EI individuals have strong emotions and attitude to deal stressful events in a positive way. The EI competencies generate the skill in individual to choose various courses of action to deal stress without collapsing, to be positive to solve a problem, and feel that one can control the situation (Slaski and Cartwright, 2002).

The EI individuals able to the proper handle the negative feelings in a way to express it positively, allowing people to interact and work together without friction to meet their targets. This ability facilitates the individual to notice timely and redirect their unconstructive stressful reactions, emotions and impulses. It is the ability to deter and to think about their reactions to events before starting work. An EI individual is a consistent and dedicated employee; open to everything new, even in the most uncertain prospects and sudden changes such as people tend to perceive as a new opportunity rather than as a threat to personal safety and suffer in stress. EI individual can keep the strike in the worst circumstances, never surrender and don't fall into panic but react carefully (Goleman, 1998). These competencies may give assistance to bank's employees to deal stress effectively.

The employees having EI competencies manage their negative emotions in the workplace and report fewer psychological problems with high levels of job satisfaction and organizational commitment (Gardner, 2005). Bar-On, Brown, Kirkcaldy, and Thome (2000) investigated the impact of EI on police officers and health-care professionals. They conclude that police officers have high EI respond to stress with better coping strategies and report less depression comparatively than health-care professionals having low EI. In another study of American and Australian college students show that students with high EI level, report fewer physical symptoms, less social anxieties and depression. They have self-esteem and interpersonal satisfaction and use active coping strategies to deal their psychological problems (Salovey, Stroud, Woolery \& Epel, 2002, Ciarrochi, Deane, \& Anderson, 2002).

\section{A. Hypothesis}

The discussion leads the assumption that there is the strong impact of EI competencies on stress in job, such that high EI individuals may overcome the stress in the workplace and ultimately play an effective role in the organizational performance. So it is hypothesized that:

$H_{1}$ There is a strong impact of EI competencies to prevent the stress in job.

\section{METHODS}

\section{A. Sample and Procedure}

The sample was randomly distributed among 23 different banks involve 3 banks from public sector banks, 18 from private sector banks and 2 from foreign banks, which have more than 3000 employees but according to the requirement, data were randomly collected from 630 employees, which fulfill the requirement of data analysis. The selected banks have branches almost in all big and small cities and catering almost most of the financial products to the customer. The data collected from 75 branches but 63 branches' data were used in this study and rest of 12 branches data were excluded from the study due to incomplete questionnaire, total other rating problems, lack of proper participation by staff, lack of management support, etc., and thus response rate was $87 \%$.

The responding branches were randomly selected throughout four big cities of Pakistan. A total of 18 branches (29\%) were responded from the Peshawar, 15 from the Islamabad (24\%), 16 from the Rawalpindi (25\%), 14 from Lahore $(22 \%)$. There were 186 respondents $(29 \%)$ from Peshawar region, 150 respondents (24\%) from Islamabad region, 156 respondents (25\%) from Rawalpindi region and 138 respondents $(22 \%)$ from Lahore region. The different categories of designation were selected beside the branch manager which is the compulsory i.e. credit manager, 
operation manager, customer service officer, sales Incharge, consumer finance officer, cashier, assistant staff, etc. Total 98 branch managers, 86 credit managers, 80 operation managers, 88 customer service officers, 71 sales Incharge, 65 consumer finance officers, 76 cashier and 66 assistant staff, etc., responded in this study. At-least 10 members randomly selected from each branch to complete the questionnaire. The respondents from each of the selected branches were contacted by personal visit, mail and e-mail messages.

\section{B. Measurement}

In this study, EI was measured by the Emotional and Social competency inventory (ESCI). The ESCI is a latest and 360-degree instrument designed to measure the emotional and social competencies of individuals and organizations, offered by the HayGroup. The ESCI consists of 72 items, which measure 12 competencies organized into four groups: self-awareness, self-management, social awareness and relationship management (Wolff, 2006). The rationale for selecting the ESCI instrument is that the instrument is basically designed for working organization and their employees. It is structured employing a six point Likert Scale ( $1=$ never, $5=$ consistently) plus sixth scale a 'not applicable' option. In this instrument, respondents were rated that how often they exhibit each behavior during official work on a self rating and other rating basis.

The stress questionnaire generated based on literature review and the empirical study of bank employees. The basic purpose of this questionnaire is measuring the stress level in the bank's employees and analyzes the relationship with EI competencies of branch managers. In this dimension, the respondents report that how much they observe the stress in their present organization and their managers/Incharge supportive role to prevent the stressful condition in the workplace. This dimension contains 10 questions and analyzes the stress level of staff. It is structured employing a 5 point Likert Scale $(1=$ strongly disagree, $5=$ strongly agree $)$ and filled by staff. The outcomes of this instrument will be used for the managers' role in the workplace that what is their level of EI and how much they are able to control the stress among employees.

\section{RESULT}

\section{A. Reliability of ESCI and Stress Instruments}

The study shows that Cronbach's alpha of ESCI instrument reported for all their competencies to range from .736 to .840 . The pilot study of stress instrument contained more than 100 respondents and arranged at 2 private sector banks. It reviewed the scales and used to measure the reliability of the instrument including 10 questions with measuring one dimension. While the empirical study contained more than 600 respondents also used to measure the reliability of the stress questionnaire scale. The pilot study shows that Cronbach's alpha of instrument reports .930 while an empirical study reports .984 . So the reliability of both instruments is acceptable and fulfills the requirement of internal consistency.

\section{B. Descriptors of ESCI and Stress Instruments}

\section{1) Assessment of ESCI}

The 72 items of ESCI instrument measure 12 competencies of EI and each competency measured by 6 items. Table 1 show the mean scores of BM on a self rating and total other rating basis and then compare with the HayGroup norm. The total other column is the mean of staff score for a branch manager. According to the result, BM gets more than the norm in positive outlook competency and show possesses this emotional competency but fell greatly lower the norm in all other competencies of EI dimensions. It shows that majority of branch manager has a lack of EI skills and competencies. The score of four dimensions is as follows;

TABLE 1: SUMMARY OF THE MEAN SCORES OF THE BM

\begin{tabular}{|c|c|c|c|}
\hline \multicolumn{4}{|c|}{ EI Competencies } \\
\hline Competencies & Mean (Self) & $\begin{array}{l}\text { Mean (Total } \\
\text { Other) }\end{array}$ & Norm \\
\hline \multicolumn{4}{|c|}{ Self Awareness } \\
\hline Emotional Self-Awareness & 3.480 & 2.785 & 3 \\
\hline \multicolumn{4}{|c|}{ Self Management } \\
\hline Achievement Orientation & 3.560 & 2.680 & 3 \\
\hline Adaptability & 3.573 & 3.271 & 4 \\
\hline Emotional Self-Control & 3.590 & 2.821 & 3 \\
\hline Positive Outlook & 3.553 & 3.196 & 3 \\
\hline \multicolumn{4}{|c|}{ Social Awareness } \\
\hline Empathy & 3.490 & 2.892 & 4 \\
\hline Organizational Awareness & 3.540 & 2.952 & 3 \\
\hline \multicolumn{4}{|c|}{ Relationship Management } \\
\hline Conflict Management & 3.553 & 2.888 & 4 \\
\hline Coach and Mentor & 3.590 & 2.057 & 3 \\
\hline Influence & 3.583 & 2.976 & 3 \\
\hline
\end{tabular}




\begin{tabular}{|l|c|c|c|}
\hline Inspirational Leadership & 3.505 & 2.958 & 3 \\
\hline Teamwork & 3.60 & 2.956 & 3 \\
\hline
\end{tabular}

\section{2) Assessment of the Stress Questionnaire}

According to table 2, the result shows the mean of credit managers, operation managers, customer service officers, sales Incharge, cashier, consumer finance officers and assistant staff, etc. It shows that all the respondents report a high level of stress and unsupportive attitude of branch manager. The lowest range is between 1.305 and 2.379 on a Likert scale of 1 to 5 suggesting that majority of employees are facing high level of stress and their related problems.

TABLE 2: SuMMARY OF THE MEAN SCORES OF STAFF MEMBER FOR THE STRESS DIMENSION

\begin{tabular}{|l|l|}
\hline \multicolumn{2}{|c|}{ Stress Questionnaire } \\
\hline Designation & Mean \\
\hline Consumer Officer & 1.603 \\
\hline Credit Manager & 2.204 \\
\hline Operation Manager & 1.305 \\
\hline Sales Incharge & 2.032 \\
\hline Customer Service officer & 2.052 \\
\hline Cashier & 1.987 \\
\hline Assistant Staff & 2.379 \\
\hline
\end{tabular}

\section{Testing of Hypothesis: EI and Stress}

The multiple regressions were used to examine the relationship between the ESCI variables and stress variable. The Pearson correlations and stepwise regression analyses were carried out in order to examine these relationships. It was employed to evaluate the predictive validity of ESCI competencies with respect to the stress variable and being evaluated in terms of what they show the impact on the dependent variable. The 12 variables of ESCI define as independent variables and stress defines as a dependent variable. Before using stepwise regression, the bivariate correlation with 2-tailed test was conducted to find out the existing of relationship. It showed the significant relationship and thus, feasible for stepwise regression. The stepwise regression result (see Table 3) was utilized for testing the hypothesis.

TABLE 3: STEPWISE MULTIPLE REGRESSION RESULTS

\begin{tabular}{|c|c|c|c|c|c|c|c|c|}
\hline Model & $\mathbf{R}$ & R Sq. & Adj. R Sq. & $\mathbf{F}$ & Sig. & B Coefficients & 't' Value & Sig. of $B$ \\
\hline 1 & $.778^{\mathrm{a}}$ & .605 & .605 & 211.130 & $.000^{\mathrm{a}}$ & .778 & 45.949 & .000 \\
\hline \multirow[b]{2}{*}{2} & \multirow{2}{*}{$.784^{\mathrm{b}}$} & \multirow[b]{2}{*}{.614} & \multirow[b]{2}{*}{.612} & \multirow[b]{2}{*}{146.830} & \multirow{2}{*}{$.000^{\mathrm{b}}$} & .442 & 11.035 & .000 \\
\hline & & & & & & .353 & 6.071 & .000 \\
\hline \multirow{3}{*}{3} & \multirow{3}{*}{$.785^{\mathrm{c}}$} & \multirow{3}{*}{.616} & \multirow{3}{*}{.615} & \multirow{3}{*}{104.830} & \multirow{3}{*}{$.000^{\mathrm{c}}$} & .378 & 9.450 & .001 \\
\hline & & & & & & .252 & 3.745 & .000 \\
\hline & & & & & & .171 & 2.732 & .005 \\
\hline
\end{tabular}

a. Predictors: (Constant), Emotional Self-Control, b. Predictors: (Constant), Emotional Self-Control, Coach and Mentor, c. Predictors: (Constant), Emotional Self-Control, Coach and Mentor, Organizational Awareness,

The process chooses 3 EI competencies, which significantly contribute in the prediction of stress. These are in order in which they entered the models, emotional self-control, coach and mentor and organizational awareness. The $\mathrm{R}^{2}$ value (see table 3 ) indicates the $60.5 \%, 61.4 \%$ and $61.6 \%$ variance in the model 1,2 and 3 respectively for dependent variable. However, the model 3 has more to do with the criterion variable as its coefficient of determination is $61.6 \%$ more than other. So the linear combination of emotional self-control, coach and mentor and organizational awareness can be predicted $61.6 \%$ variance in the criterion variable which indicates the strong relationship.

To test the null hypothesis, the analysis of variance $\mathrm{F}$ calculations is $211.130,146.830$, and 104.830 respectively and the p-value (associated with F value) is very small 0.000 in all models. In indicates that the null hypothesis is rejected 
for all cases and the alternative hypothesis is accepted. So far, it has been shown that there is a linear relationship between the dependent variable and independent variables. It is also noted that $t$ " value for $B$ coefficient is significant in all models $(\mathrm{p}<.05)$, no doubt that the $\mathrm{B}$ coefficients are reliable parameters and the variations explained by the model is not due to chance. It also indicates a significant relationship to the criterion variable.

Further, if variance inflationary factor (VIF) is greater than 10 , signify that there is an excessive correlation between all the independent variables (Levine, David, Berenson, Mark, Stephan \& David, 1997). Therefore, the third regression model, in which VIF value is less than 10 shows not problematic and thus chooses. Furthermore, the collinearity diagnostics confirm that there is no problems with multicollinearity values as the third regression model condition index value is less than 15 (Tabachnick and Fidell, 2007).

\section{DISCUSSION}

\section{A. ESCI competencies}

The results exhibits that branch manager don't give the impression to satisfy the requirements for all the EI dimensions. The BM gets the score less than the norm in all the competencies except positive outlook. It indicates that majority of branch managers has a lack of ability to understand internal states, own feelings and emotions, and unable to asses the impact on others. They are unable to control their negative feeling and respond to sudden changes in branch. It shows the weakness of branch managers' behavior and attitude in the workplace.

They have the lack of skills to capturing the understanding of feeling and opinion of others and unable to take an active interest in their concerns and problems. The empathy competency is important for better job performance because interactions with people are necessary (Goleman, 1998). It is necessary for branch managers in the banking sector which is basically service sector and customer dealing is most important job in this sector. They are predicted weak in understanding and steering of the organization which is important for its success. They have the lack of skill to inspire employees, creating teamwork spirit and handle the conflict among employees.

\section{B. Stress Instrument}

According to table 2, the results put on views that branch managers are perceived unsupportive and uncooperative in order to reduce the stressful situations among employees. The data indicates that the stress level is very high in employees. However, managers are unable to take a step to minimize the stress and provide helping hand to employees to handle stress, even they generate more stress. Therefore, they don't feel the strong sense of belonging to their respective organizations and want to move in another organization. Although the salary package and other benefits are very attractive to bank employees, but they have thought many times about leaving organization.

\section{ESCI competencies and stress}

The relationship between EI competencies and stress was analyzed by stepwise multiple regression method. According to table 3 , the adjusted $\mathrm{R}^{2} 61.5 \%$ was obtained in the third model, that show the strong relationship. It indicates $61.5 \%$ variation in the dependent variable stress by three prediction variables emotional self-control, coach and mentor and organizational awareness. It means that three competencies are found to give impact on the stress level. While according to table 4 , the branch manager got mean 1.937 in stress as well as 2.821 mean in emotional self-control, 2.952 mean in the organizational awareness and 2.057 mean in coach and mentor, which are less than the required norm.

The outcome shows that majority of the branch managers is deficient in EI competencies. Therefore, they have the lack of skill to prevent stress among employees. It proves the assumption that EI competencies may reduce the occurrence of stress in the workplace because mostly branch managers are unable to manage own and other emotions in the workplace. Therefore, staff report psychological problems and unsupportive behavior of branch managers. It also proves the assumption that branch manager with high EI level can control and manage negative emotions and feelings of employees in the workplace and prevent the outcome of stress.

TABLE 4: ESCI COMPETENCIES AND STRESS

\begin{tabular}{|l|c|c|c|c|}
\hline \multirow{3}{*}{ Designation } & OPQ Dimension Mean & \multicolumn{3}{|c|}{ Emotional Intelligence Competencies Mean } \\
\cline { 2 - 5 } & $\begin{array}{c}\text { Stress (Average Score of } \\
\text { Staff) }\end{array}$ & $\begin{array}{c}\text { Emotional Self } \\
\text { Control }\end{array}$ & $\begin{array}{c}\text { Organizational } \\
\text { Awareness }\end{array}$ & Coach and Mentor \\
\hline $\begin{array}{l}\text { Branch } \\
\text { Manager }\end{array}$ & 1.937 & 2.821 & 2.952 & 2.057 \\
\hline
\end{tabular}

\section{CONCLUSION:}

The study addresses the psychological problems of employees and seeks to the solution in the light of EI competencies. The outcomes show that the EI competencies have the positive and strong impact on stress. It concludes that more than $75 \%$ employees of banking sector experience stress on daily basis and demand from high management to solve the root causes of stress on the priority basis. It concludes that high EI managers can control the level of stress among employees. The selected employees used for the research study showed the positive response and took a keen interest to participate, and willing to learn and explore personal EI capabilities and skills. Also, the study concludes that an investment in the EI training program to develop the EI level of employees either manager or peer, might have 
provided the most advantages and benefit not only to improve the individual performance but also increase the organizational performance.

\section{RECOMMENDATION FOR FUTURE RESEARCHES:}

Although there is no limit to identify the recommendations but some suggestions for both researchers and managers can be recommended based on the results of this research study. The outcomes emphasize that we should not only be limited to stress factor but also try to find out the new different relationship with EI competencies. It should be explored in the impact of EI competencies on different types of occupational problems i.e. teamwork, leadership, conflict management, retention, etc. There is a need to develop EI competencies in individuals for improving workplace's performance and practices. The benefits of EI competencies should be explored in other industries beyond the banking sector and this research study can be first drop of rain.

It also suggests that there is a need to arrange the training program for managers and peers so that they can increase their skill and actively participate in the organization. The outcomes reveal that the majority of managers have the lack of EI competencies, and they face numerous problems in the start of their career. So it should not only start the training program of EI in the level of organization but also establish and include the training program for young graduates in academic institutions. There are many training programs for workplace and educational institutions have already been developed in European countries and outputs are very productive and effective. So there is also needed to research on develop and construct the training program according to our norm, problems and working environment.

\section{REFERENCES}

[1] Akinboye, J. O., Akinboye, D. O. \& Adeyemo, D. A. (2002). Coping with Stress in Life and Workplace. Ibadan: Stirling-Horden Publishers.

[2] Bar-On, R. (2003). How important is it to educate people to be emotionally and socially intelligent, and can it be done? Perspectives in Education, 21 (4), 3-13.

[3] Cartwright, S. (2000). Taking the pulse of executive health in the UK. The Academy of Management Executive, 14, 16-24.

[4] Ciarrochi, J, Chan, A \& Bajgar, J. (2001). Measuring emotional intelligence in adolescents. Personality and Individual Differences, 28, 539-561.

[5] Ciarrochi, J., Deane, F.P., \& Anderson, S. (2002). Emotional intelligence moderates the relationship between stress and mental health. Personality and Individual Differences, 32, 197-209.

[6] Economic Survey of Pakistan 2008 - 09, Ministry of Finance, Government of Pakistan.

[7] Gardner, L. (2005). Emotional intelligence and occupational stress. Unpublished doctoral dissertation, Swinburne University of Technology, Melbourne, Australia.

[8] Goleman, D. (1998). Working with Emotional Intelligence. New York: Bantam Books.

[9] Hochwarter W. A., Perrewe P. L., Meurs J. A. \& Kacmar C. (2007). The interactive effects of work-induced guilt and ability to manage resources on job and life satisfaction. Journal of Occupational Health Psychology. 12, 125-135.

[10] Kazmi R., Amjad S. \& Khan D. (2008). Occupational stress and its effect on job performance: A case study of medical house officers of district Abbottabad. Journal of Ayub Medical College. 20, 135-139.

[11] Levine, D, M., Berenson, M. L. \& Stephan, D. (1997). Statistics for Managers Using Microsoft Excel. New Jersey: Prentice Hall.

[12] Salovey, P., Stroud, L. R., Woolery, A., \& Epel, E. S. (2002). Perceived emotional intelligence, stress reactivity, and symptom reports: Further explorations using the Trait Meta-Mood Scale. Psychology and Health, 17, 611-627

[13] Slaski, M. and Cartwright, S. (2002). Health, performance and emotional intelligence: An exploratory study of retail managers. Stress and Health, 18, 63-68.

[14] Spector, P. E., \& Goh, A. (2001). The role of emotions in the occupational stress process. In P. L. Perrewe \& D. C. Ganster (Eds.), Exploring Theoretical Mechanisms and Perspectives (pp. 195-232). New York: JAI.

[15] Tabachnick, B. G. \& Fidell, L. S. 2007. Using multivariate Statistics. Boston: Pearson Education.

[16] Wolff, S. B. (2006). Emotional Competence Inventory 2.0 (ECI 2.0): Technical Manual. Boston: HayGroup. 